\title{
Analysis of supply-chains in the circular economy by means of VSM
}

\author{
Jeff Mangers, Peter Plapper
}

The Circular Economy (CE) concept aims to close resource loops and keep resources in the system for as long as possible at the highest utility level, without neglecting the goals of sustainable development. This paradigm shift from a finite and linear to a circular economy is however only possible if systems can be viewed as holistic overall systems. Thus, preventive problems can be identified and located as early as possible and counteracting measures initiated.

This paper presents a new value stream mapping (VSM) model to consider interrelated processes in a holistic manner, regarding the requirements of $\mathrm{CE}$. To do so, one macro-level to consider interrelated company relationships together with a respective micro-level to consider the individual company specific processes are elaborated. The degree of circularity is determined based on the $9 \mathrm{R}$ framework and new visualizations and measurement indicators are added at the different levels. This new model helps to mainly identify hurdles at a product's end-of-life, which are preventing a circular flow of resources, worth sharing with the responsible of a product's beginning-of-life. The model itself is validated by an extensive cross-company PET-bottle case study in Luxembourg.

\section{Introduction}

The Circular Economy (CE) concept aims to close and slow resource loops (Moraga et al. 2019) and avoid waste (Di Maio et al. 2017), without neglecting the goals of sustainable development (Azevedo, Godina, and Matias 2017). Recently, the concept has received encouraging attention among researchers and economists (Merli, Preziosi, and Acampora 2018) as a suitable solution to move from the finite linear economic concept to a more sustainable one (Bocken et al. 2017). In addition to the lack of an internationally accepted definition for CE (Kirchherr, Reike, and Hekkert 2017), there are a number of other barriers and hurdles (e.g., technical, cultural, market, and regulatory barriers) (Grafström and Aasma 2021) that prevent a successful shift from a linear to a circular economy. Generally speaking, this paradigm shift is only possible if systems can be viewed as holistic and thus preventive problems can be identified and located as early as possible. Methods such as life-cycle assessment (LCA) or material flow analysis (MFA) are 
better suited for static considerations and not for the desired holistic visualization, which is why a new visualization method is needed.

Value stream mapping (VSM) is a commonly known lean methodology (Mangers, Thoussaint, et al. 2020) that is used to visualize the current state of material and information flows within an organization in order to find weaknesses and improve process flows (ISO 22468 2020). The aim of this paper is to present a new VSM model that can assess and visualize interrelated processes related to the circular economy at macro (supply chains) and micro (individual company) levels. To this end, new indicators and visualizations are incorporated into the traditional VSM model that provide a new circular perspective on resource flows within supplychains (SCs) and within companies.

The assessment indicators are divided into direct (CE) and indirect (sustainability - environmental, economic, and social) indicators. The selection refers to indicators of sustainability VSMs as well as a systematic literature research regarding CE indicators (182 in total, future publication on this is planned). The data collection is an important and elaborate part of the VSM analysis, which takes place during a company visit. The first step is to try to understand the general process flow before process specific data is recorded. Company critical data must not be shared with other SC partners under any circumstances.

The goal of the macro-level visualization is to provide a holistic overview of the entire supply chain. To illustrate the circular value of the targeted cycle, the 9R framework (e.g., R3-reuse, R8-recycle, etc.) (Kirchherr et al. 2017) has been inserted as a value ladder and thus helps to make the value of each company easily recognizable. The 9R framework can be understood as the 'how-to' of CE, with as the main feature a hierarchy, where the first $\mathrm{R}$ ( $\mathrm{R} 0$-refuse) is considered a priority over the second R (R1-rethink) and so on. The additional data fields provide insight into the respective company consumption as well as the total consumption. On a micro level, the adapted visualization is mainly used to illustrate the internal resource flows. Thus, not only the main material flow is shown, but also additional flows such as the packaging or additional material flow. Resource in- and outflows can be an indication for potential CE improvements, mainly with regard of waste flows. The data fields provide an insight into the respective process as well as the total consumption. 


\section{Methodical procedure}

Figure 1 visualizes the methodological approach of this paper.

Objectives:

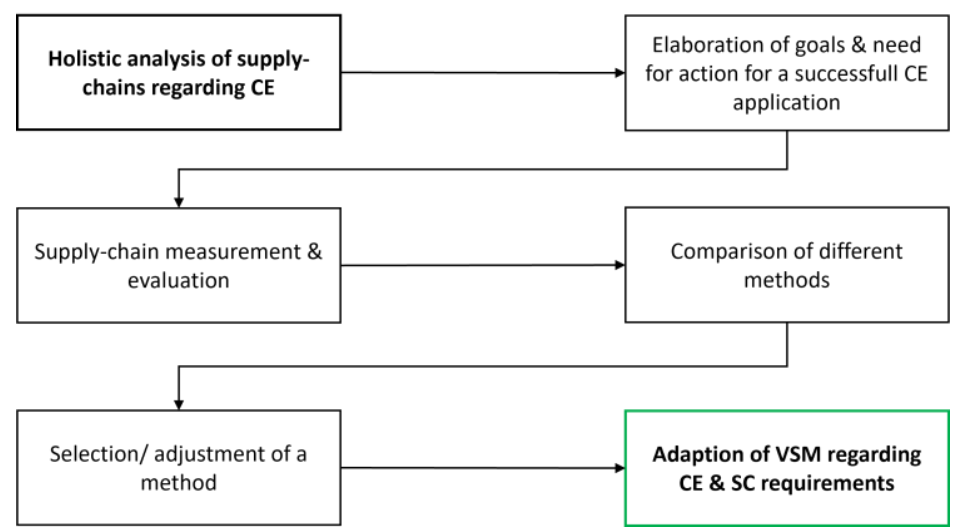

Figure 1: Methodical procedure
Tasks:

Elaboration of goals \& need application

aption of VSM regarding CE \& SC requirements

The left side lists the main goal (top left) and the intermediate goals, and the right side lists the intermediate task and the main task (bottom right). Each given goal contains a corresponding task. The main objective was a holistic analysis of supply chains with respect to their circularity. For this purpose, three CE objectives, as well as two application fields with a need for action were elaborated (Mangers, Minoufekr, and Plapper 2021). The three main CE objectives are as follows:

1. Close and slow loops (Sensu stricto) (Moraga et al. 2019),

2. Minimize waste (Morseletto 2020),

3. Sustainability (Sensu latu) (Kirchherr et al. 2017) with the two fields of action:

1. Identifying the needed collection, sorting, and R-infrastructure,

2. Developing circular product design guidelines.

This results in the need for an improved information exchange between end-oflife (EOL) and beginning-of-life (BOL), which is required to initiate a successful paradigm shift. This is set as the objective of the holistic VSM visualization.

As an intermediate goal based on this, the measurement and evaluation of supply chains with respect to their circularity is set, which entails a comparison of different methods (to be explained in a future publication), with the aim of finding a suitable method. VSM was selected, with the requirement and main task of this paper to adapt the VSM method regarding CE and SC aspects. For this purpose, first an extensive literature review (inspired by Fink (Fink 2019) was performed 
regarding the already existing visualization and design possibilities using VSM. The results are shown in Table 1.

The research methodology is analytical and the case study structure is based on Yin methodology (Yin 2018). The data collection was conducted, during 10 different company visits, all part of a supply chain network of a PET bottles in Luxembourg.

The next section looks at the theoretical background of VSM before Chapter 4 addresses the macro- and micro-level results. The final chapter summarizes the main points and provides an outlook for future work.

\section{Theoretical background}

The basic VSM concept was developed by (Rother and Shook 1999) and further details regarding defined calculation procedures were provided by (Erlach 2013). To ensure a common understanding of the most important VSM symbols, parameters and calculation procedures, VSM has been standardized by ISO (Mangers, Oberhausen, et al. 2020).

Basically, VSM visualizes the flow of materials and information within a company, focusing on time. Beyond that, however, other fields of application have been pursued, and the consideration of CE is not an entirely new idea. (Edtmayr, Sunk, and Sihn 2016) incorporated three reuse cycles (reuse, recycle, recovery and disposal) for waste materials into VSM. (Galvão et al. 2020) focused mainly on connecting value streams within circular business models and their ecosystems rather than measuring the circularity of value streams. (Hedlund et al. 2020) explored how companies and industrial systems and networks can use value stream mapping as a tool to improve sustainability and accelerate the shift towards a green, circular economy. However, none of the mentioned authors focused on measurement and evaluation, as well as holistic analysis of CE using VSM.

In addition, much emphasis has recently been placed on linking VSM with sustainability (Edtmayr et al. 2016) as well as other complementary indicators. Table 1 summarizes the indicators currently included in VSM.

\begin{tabular}{|l|l|l|c|c|}
\hline Category & Sub-category & Metrics, example & Unit & Reference \\
\hline \multirow{3}{*}{$\begin{array}{l}\text { Emissions } \\
\text { (env.) }\end{array}$} & Air-emissions & $\begin{array}{l}\text { Nitrogen oxides, } \\
\text { heavy metal }\end{array}$ & $\mathrm{kg}$ & (Paju et al. 2010) \\
\cline { 2 - 5 } & Environment & $\begin{array}{l}\text { Multidimensional, } \\
\text { connections within } \\
\text { the SC }\end{array}$ & dif. & $\begin{array}{c}\text { (Lorenzon dos Santos et al. } \\
\text { 2019) }\end{array}$ \\
\cline { 2 - 5 } & Water-emissions & $\begin{array}{l}\text { Chemical oxygen } \\
\text { demand }\end{array}$ & $\mathrm{kg}$ & (Paju et al. 2010) \\
\hline $\begin{array}{l}\text { Energy } \\
\text { (env.) }\end{array}$ & $\begin{array}{l}\text { Energy type/ } \\
\text {-consumption }\end{array}$ & $\begin{array}{l}\text { Electricity, heat, } \\
\text { cooling }\end{array}$ & $\begin{array}{c}\mathrm{kWh}, \\
\mathrm{MJ}\end{array}$ & (Paju et al. 2010) \\
\hline
\end{tabular}




\begin{tabular}{|c|c|c|c|c|}
\hline & Dual energy & Idle processing run & $\mathrm{kWh}$ & $\begin{array}{l}\text { (Müller, Stock, and Schillig } \\
\text { 2014) }\end{array}$ \\
\hline \multirow{5}{*}{$\begin{array}{l}\text { Material } \\
\text { (env.) }\end{array}$} & New material & $\begin{array}{l}\text { Steel, packaging } \\
\text { material }\end{array}$ & $\mathrm{kg}$ & (Paju et al. 2010) \\
\hline & Recyclate & rPET & $\mathrm{kg}$ & (Garza-Reyes et al. 2018) \\
\hline & $\begin{array}{l}\text { Additional } \\
\text { material }\end{array}$ & $\begin{array}{l}\text { Lubricating oil, } \\
\text { compressed air }\end{array}$ & $\begin{array}{c}\mathrm{m} 3, \\
\mathrm{~kg}\end{array}$ & (Paju et al. 2010) \\
\hline & Waste & $\begin{array}{l}\text { Waste oil, waste } \\
\text { materials }\end{array}$ & $\mathrm{kg}$ & (Paju et al. 2010) \\
\hline & Scrap & Quality problems & $\begin{array}{l}\mathrm{kg}, \\
\mathrm{pc}\end{array}$ & (Edtmayr et al. 2016) \\
\hline \multirow{2}{*}{$\begin{array}{l}\text { Transport } \\
\text { (env.) }\end{array}$} & $\begin{array}{l}\text { Internal } \\
\text { transportation }\end{array}$ & Between processes & $\mathrm{m}$ & (Garza-Reyes et al. 2018) \\
\hline & $\begin{array}{l}\text { External } \\
\text { transportation }\end{array}$ & $\begin{array}{l}\text { Between } \\
\text { production plants }\end{array}$ & $\begin{array}{c}\mathrm{m}, \\
\mathrm{CO} 2\end{array}$ & (Garza-Reyes et al. 2018) \\
\hline $\begin{array}{l}\text { Water } \\
\text { (env.) }\end{array}$ & $\begin{array}{l}\text { Water } \\
\text { consumption }\end{array}$ & Cleaning water & $\mathrm{m} 3$ & (Faulkner and Badurdeen 2014) \\
\hline \multirow{3}{*}{$\begin{array}{l}\text { Data } \\
\text { (eco.) }\end{array}$} & Industry 4.0 & Multidimensional & dif. & (Huang et al. 2019) \\
\hline & Information flow & $\begin{array}{l}\text { Information up- } \\
\text { and download }\end{array}$ & dif. & $\begin{array}{l}\text { (Mangers, Thoussaint, et al. } \\
\text { 2020; Meudt, Metternich, and } \\
\text { Abele 2017) }\end{array}$ \\
\hline & Supply-chains & Multidimensional & dif. & $\begin{array}{l}\text { (Matt, Krause, and Rauch } \\
\text { 2013; Megayanti, Anityasari, } \\
\text { and Ciptomulyono 2018) }\end{array}$ \\
\hline \multirow[t]{2}{*}{$\begin{array}{l}\text { Costs } \\
\text { (eco.) }\end{array}$} & Unit costs & $\begin{array}{l}\text { Material-, energy } \\
\text { costs }\end{array}$ & $€$ & (Paju et al. 2010) \\
\hline & Investment costs & Machine, robot & $€$ & (Paju et al. 2010) \\
\hline \multirow{5}{*}{$\begin{array}{l}\text { Production } \\
\text { (eco.) }\end{array}$} & Efficiency & OEE & $\%$ & $\begin{array}{c}\text { (Dadashnejad and } \\
\text { Valmohammadi 2019) }\end{array}$ \\
\hline & Make-to-order & Takt time & $\mathrm{s}$ & $\begin{array}{l}\text { (Mudgal, Pagone, and Salonitis } \\
2020)\end{array}$ \\
\hline & Multilayer & Multidimensional & dif. & (Lourenço et al. 2016) \\
\hline & Quantity & Pieces & $\mathrm{pc}$ & (Paju et al. 2010) \\
\hline & Time & $\begin{array}{l}\text { Process time, lead } \\
\text { time }\end{array}$ & $\mathrm{s}$ & (ISO 22468 2020) \\
\hline \multirow{2}{*}{$\begin{array}{l}\text { Surround- } \\
\text { ings } \\
\text { (soc.) }\end{array}$} & Employees & $\begin{array}{l}\text { Number of work- } \\
\text { ers, work loss }\end{array}$ & \# & (Paju et al. 2010) \\
\hline & Customer service & $\begin{array}{l}\text { Number of com- } \\
\text { plaints }\end{array}$ & $\begin{array}{l}\mathrm{pc} / \\
\text { year }\end{array}$ & (Paju et al. 2010) \\
\hline \multirow[t]{3}{*}{$\begin{array}{l}\text { Load } \\
\text { (soc.) }\end{array}$} & $\begin{array}{l}\text { Working } \\
\text { environment }\end{array}$ & $\begin{array}{l}\text { Physical Load } \\
\text { Index (PLI) }\end{array}$ & $\#$ & $\begin{array}{l}\text { (Faulkner and Badurdeen } \\
\text { 2014)(Kuhlang et al. 2014) }\end{array}$ \\
\hline & Risk categories & $\begin{array}{l}\text { Electrical, } \\
\text { chemicals, } \\
\text { pressure, speed } \\
\end{array}$ & \# & (Faulkner and Badurdeen 2014) \\
\hline & Noise level & Machinery noise & $\mathrm{dB}$ & $\begin{array}{c}\text { (Vinodh, Ben Ruben, and } \\
\text { Asokan 2016) }\end{array}$ \\
\hline \multirow[b]{2}{*}{$\begin{array}{l}\text { Conversion } \\
\text { factor }\end{array}$} & CO2-equivalent & $\mathrm{kWh}$ to $\mathrm{CO} 2-\mathrm{eq}$ & $\begin{array}{l}\mathrm{CO} 2- \\
\text { eq. }\end{array}$ & (Edtmayr et al. 2016) \\
\hline & Scaling factor & $\begin{array}{l}\text { Compensation } \\
\text { small numerical } \\
\text { value }\end{array}$ & $\#$ & (Roosen and Pons 2013) \\
\hline Simulation & DES \& LCA & Multidimensional & dif. & (Paju et al. 2010) \\
\hline
\end{tabular}




\begin{tabular}{|l|l|l|c|c|}
\hline & $\begin{array}{l}\text { Simulation prod- } \\
\text { uct development }\end{array}$ & Time, share & s, \% & $\begin{array}{c}\text { (Ciarapica, Bevilacqua, and } \\
\text { Mazzuto 2016) }\end{array}$ \\
\hline
\end{tabular}

Table 1: Summary of indicators currently included in the VSM, with focus on sustainability (env.: environmental, eco.: economic, soc.: social, add.: additional)

To provide a holistic view, VSM will be applied at four different levels in the following (Oberhausen 2018; WBCSD 2018):

1. Nano: smallest possible level of analysis at which products and components are located.

2. Micro: Level at which companies and consumers stand

3. Meso: level that represents cross-industry and cross-company (intercompany) networks

4. Macro: highest level of analysis, where cities, countries and international agencies are located.

The following articles were used as references for mapping supply chains using VSMs: SCs-VSMs (Anderson 2017; Costin-Weiterschan/ Matiou 2017; SuarezBarraza et al. 2016), sustainable SC-VSMs (Megayanti et al. 2018) and circular SCvisualizations (González-Sánchez et al. 2020).

More detailed explanations of the individual values of the 9R framework, can be seen in Figure 2. The hierarchy refers to the waste/value hills, which establishes a priority order of what represents the best overall environmental option in waste legislation and policy (European Parliament and Council of the European Union 2008).

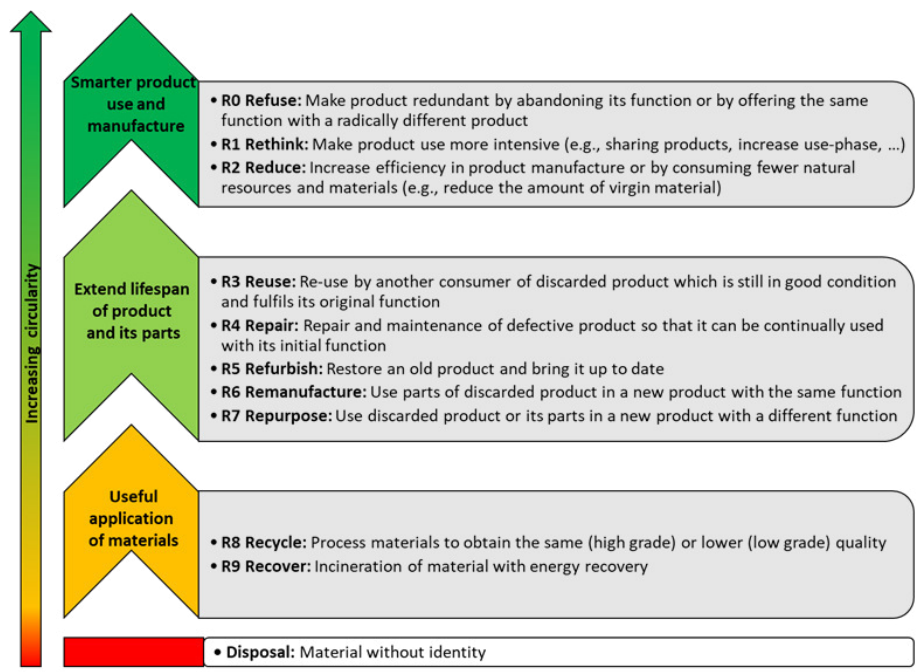

Figure 2: 9R framework, adapted from (Kirchherr et al. 2017) 
The overall goal of $\mathrm{CE}$, which aims to maintain products, components, and materials at their highest utility and value at all times, is divided into a technical and biological cycle. An often used representation of the $9 \mathrm{R}$ framework in relation to the two cycles is the butterfly diagram from the Ellen MacArthur Foundation (EMF 2015), which can be seen in Figure 3.

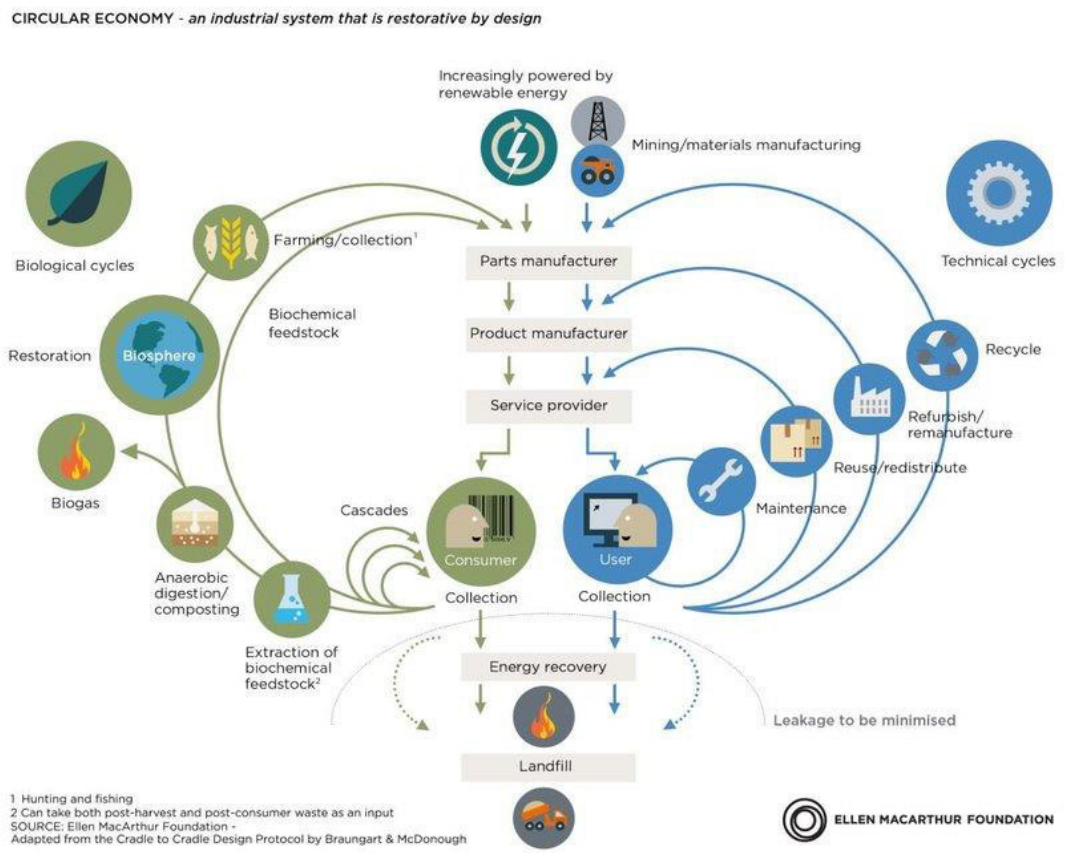

Figure 3: Butterfly diagram, sketch of a CE-technical \& biological cycle (EMF 2015)

In the next section, the aforementioned findings are integrated into a holistic VSM model that meets the requirements of $\mathrm{CE}$.

\section{Results}

The results are presented in a top-down approach. This means that first the new VSM model is explained on a macro-level (whole SC) before the model is deepened on a micro-level (company). The interrelationships and representations are illustrated by means of an extensive case study of PET-bottles within Luxembourg. 


\subsection{Macro-level analysis}

The macro VSM visualization is quite different from traditional VSMs. The main issues were how to map a circular flow of resources and how to insert a CE value representation. Both goals were achieved through inspiration from the Swim-Lane alternative (see ISO 22468:2020, p. 30) and incorporation of the 9R framework. Each level of the Swim-Lane diagram represents a particular CE value, and the lowest level defines the overall VSM value. The 9R framework is included as a vertical value ladder on the right side of the diagram, ranging from $\mathrm{R} 0$ (highest value) to R9 (lowest value).

Since the three highest Rs (refuse, rethink, and reduce) are only achievable through adaptive design, they are shown as one value at the design level. The second value is the actual use phase, where the product has its highest value. All other Rs are included until the last one, disposal, which has no CE value and should be avoided.

Each SC partner is visualized as a process box with a corresponding data box containing information from the micro-analysis. The OEM is visualized as ISO 22468 customer and the direct (e.g., PET-bottle, HDPE closure) and indirect (e.g., additional packaging film) supplier as ISO 22468 supplier. The user has a new symbol. Depending on the respective level, different information is displayed within the data boxes (see Figure 5 \& Figure 6). As the total value is defined during the collection and sorting process (compare glass and PET disposable bottle), this process ranges from R3 to disposal. Resource flows between two SC partners are color coded and complemented by a corresponding transport symbol. A final addition is the inclusion of two information flows, $\mathrm{D}$ - (active in product/process design) and R-information flow (active in resource take-back), as well as the inclusion of certain basic process characteristics (e.g., functional unit, material, etc.) that define the product under consideration. This is an important addition as it helps to locate responsibilities within the supply chains and represent them in a simple way. This can be beneficial to identify missing links and information exchanges between companies active at the beginning of the product life cycle (BOL) and those active at the end of the product life cycle (EOL). For example, in the case study cited, it is evident that there is no exchange of information between the EOL and BOL that ensures that the design of the bottles produced meet the reintroduction criteria. Thus, during sorting, the bottles may end up in a resource stream for another product (e.g., green: clothing industry).

The selected indicators are divided into two major subgroups. The first subgroup relates to $\mathrm{CE}$ (direct) and the second to the three sustainability pillars (environmental, economic, and social - indirect), shown in Figure 4. The indicators are interrelated (e.g., electricity consumption and transport volumes \& distance are converted to CO2-eq), as well as from one level to the levels above. The division of indicators into direct and indirect is based on the three main CE goals 
mentioned in chapter 2 . The indicators were partly selected from Table 1 and from a list of $182 \mathrm{CE}$ indicators obtained from a systematic literature review.
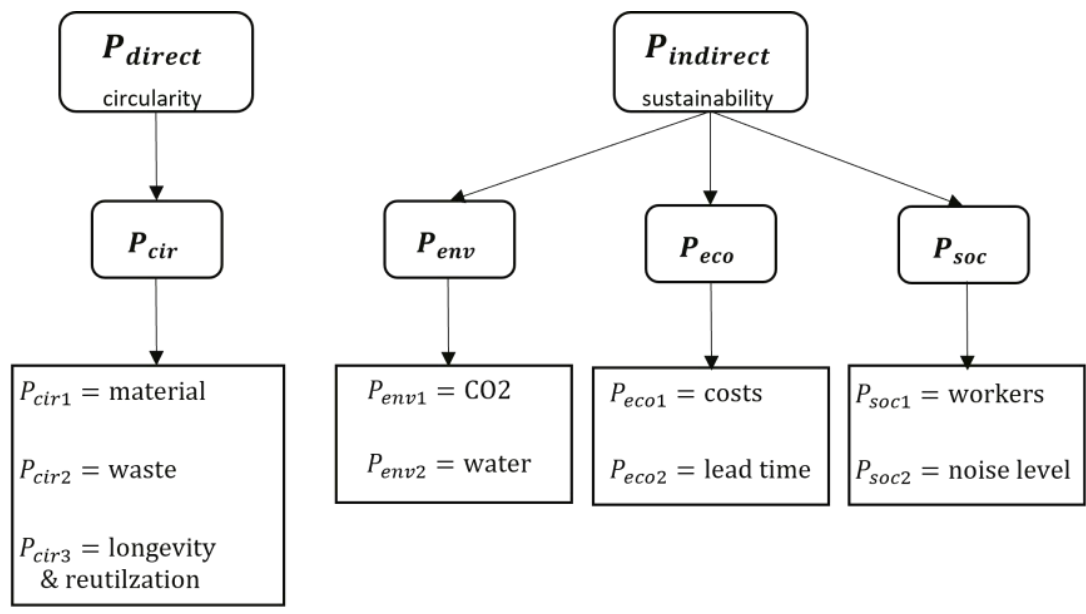

Figure 4: Subdivision of indicators

However, since there is currently no internationally accepted definition of CE, let alone a list of indicators that measure the circularity of products or supply chains, the selected indicators are subject to change. In order to keep the number of indicators manageable and based on the product requirements, the selection in this case fell on the nine indicators shown in Figure 4.

Generally speaking, this new representation helps to depict and view supply chains holistically. It allows to better understand the interrelationships within a supply chain and to trace the connections and dependencies among the individual companies. The data summary of the individual SC partners makes it easy to see which company has the greatest potential for improvement (e.g., if the goal is to improve CO2 emissions, it makes sense to start with the company responsible for the highest CO2 emissions). The color coding also makes it easy to identify the individual resource flows.

Figure 5 visualizes the adapted VSM on a macro level using a PET-bottle case study. The SC partner (water bottler) marked in blue is explained in more detail at the micro level and the data is anonymized. In this example, the dashed line between 'Collection \& Sorting' and 'Flake-prod.' indicates that recycling of the material is theoretically possible but will not be the case due to the color sorting and associated material flows in Luxembourg. Thus, while the PET-bottle itself consists of recycled material, due to the color, reuse within the packaging industry will not be the case. This is mainly due to the lack of information exchange between EOL and BOL. 


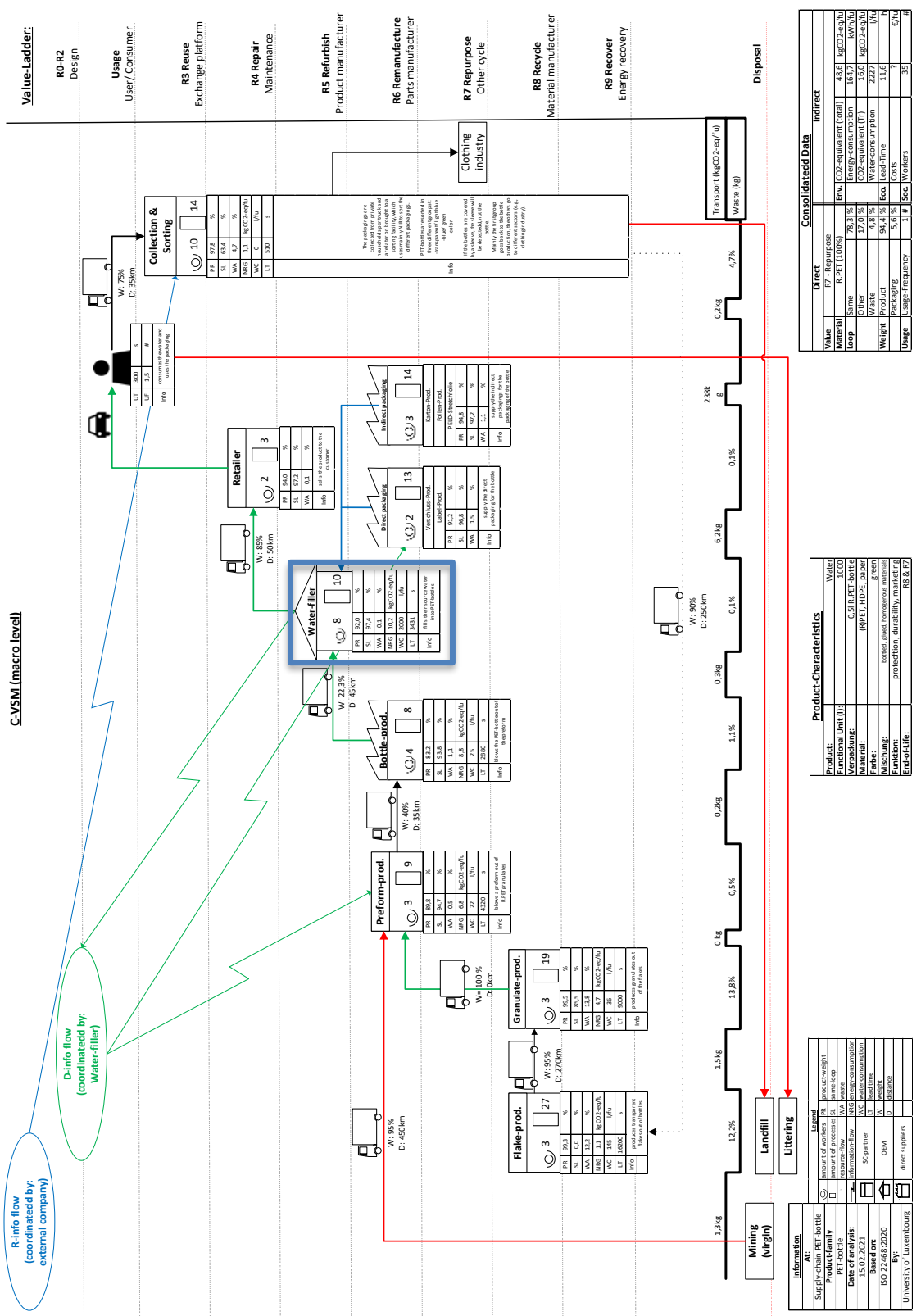

Figure 5: VSM at macro-level 


\subsection{Micro-level analysis}

The micro VSM differs slightly from the traditional VSM. The main differences are the new indicators and the visualization of additional material flows. The material flows, like the suppliers, are divided into four different groups, which are color-coded. The first group represents the actual product (e.g., water; green), the second group the direct inputs (e.g., bottle, cap, and label; blue), the third the indirect inputs (e.g., additional film packaging; red) and auxiliary materials (e.g., glue; black). Output streams and customers are also divided into three groups: resources that remain in the same loop (e.g., packaged bottles; black), resources that go to other loops (e.g., PET waste; blue), and waste (e.g., film packaging; red). The traditional information flow is kept, and the $\mathrm{D}$ and $\mathrm{R}$ information flow are added in addition to see if there is a connection between the two.

Just as at the macro-level, the indicators used are divided into two main groups (direct and indirect, see Figure 4) and are illustrated in Figure 6 using the example of a water-filler within the case study. The abbreviations of the individual indicators are explained in the appendix. There are relationships between micro and macro data and the indicators are mostly based on a functional unit. CO2 equivalents are calculated using national conversion factors and are used as a rough guide. The data itself and the names are fictitious in order not to share critical information.

The micro-level representation is structured in such a way that the results of the analysis can flow directly into the higher-level macro-level diagram. Thus, the indicators of the individual processes are added up to an overall value for the company and, if necessary, converted (e.g., electricity consumption to CO2-eq.). This result can thus be included directly in the macro-level view, while retaining the advantages of a traditional VSM and extending them through holistic adjustments.

In the case study example, it can be seen that the 'Foil Wrapping' process (high temperature application) is responsible for much of the energy consumption, although this is an indirect packaging process. The loops and weights within the summary contain interesting information. Here it can be seen that there is a small amount $(2.5 \%)$ of scrap which is inserted into the national 'Collection \& Sorting' and only a very small amount $(0.1 \%)$ cannot be reused and is designated as waste. In the weight breakdown, it can be seen that packaging (direct and indirect) represents only a small portion ( $8 \%$ ) of the total weight. This is a significant difference compared to a glass bottle, where the packaging share was over $40 \%$ for the same company. 

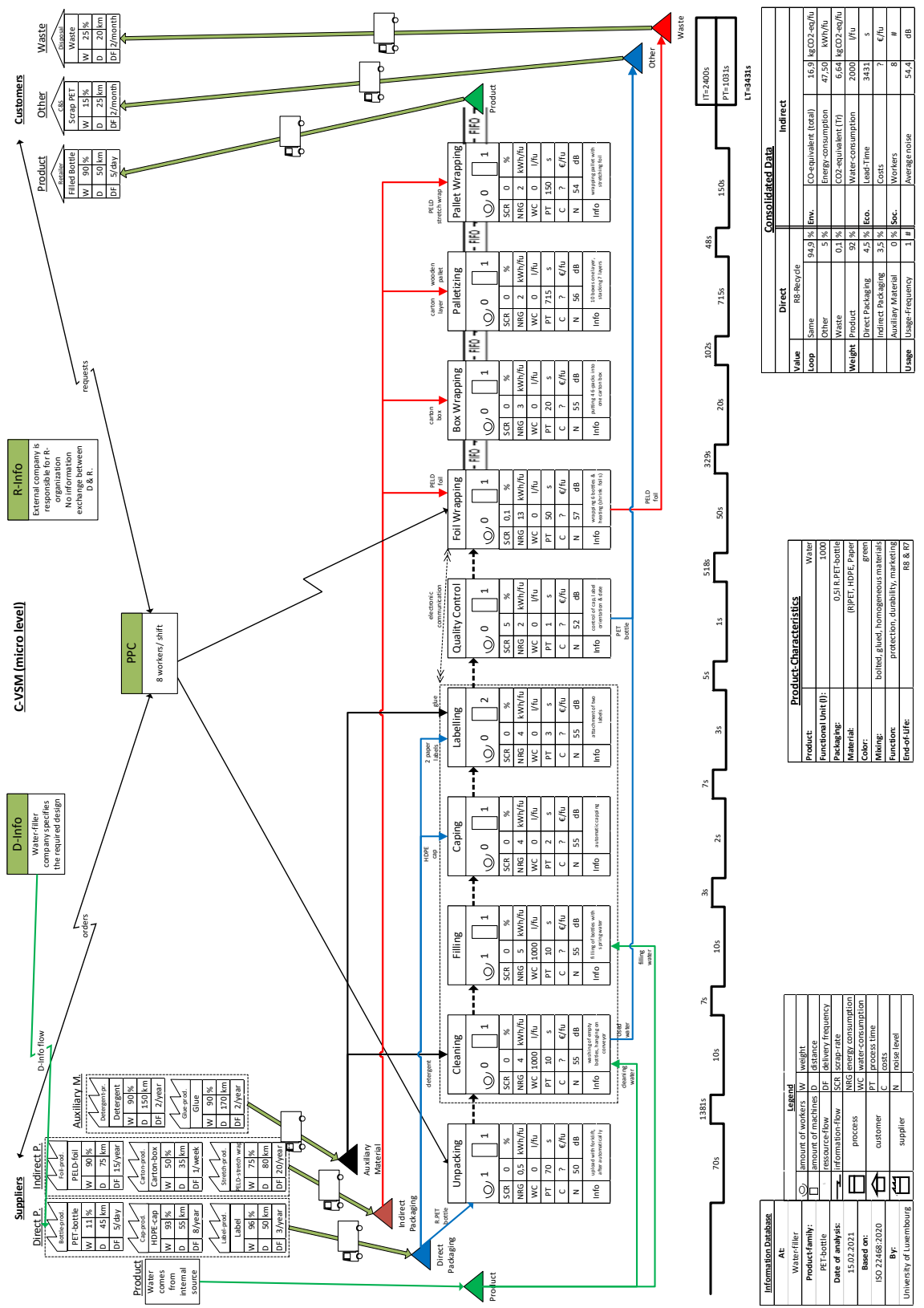

Figure 6: VSM at micro-level 


\section{Discussion \& Outlook}

In this paper, a new VSM visualization at macro- and micro-level related to CE has been presented. Even though there have been first attempts to include CE in VSM, none of the authors applied the traditional VSM method to visualize and evaluate the current state of resource flows according to CE, which is an important step for later analysis and optimization. The current state mainly helps to visualize possible weak points.

In a first step, the new VSM visualization has been applied within an extensive packaging use case and focuses primarily on one main resource flow. Therefore, the model should be verified in other use cases and further research is needed to focus on more than just the main resource flow. Currently, MS-Visio is used to draw the VSM and a connection to MS-Excel is included for data processing. As this is not an ideal solution especially in terms of analysis and optimization, this should be changed in the future. In addition, data collection is currently very timeconsuming, as the individual pieces of information must be collected during visits and are often not available (e.g., electricity consumption of individual processes). This could be facilitated in the future by independent data entry by the companies. In addition, this would enable time series recording, which is currently seen as one of the main criticisms of VSM analyses.

Overall, this work has presented a valuable extension of the current VSM application to help make the shift from a linear to a circular economy by considering interrelated process chains in a more holistic manner. Additionally, this use case of a complete SC is innovative and can help to further promote the importance of a holistic approach in analyzing current CE problems.

The set goal of evaluating and analyzing interrelated process chains in terms of CE at different levels was met. The indicators shown in Figure 5 and Figure 6 were chosen with respect to this specific case study in order to best address the needs of the industry. For other studies, other indicators may need to be chosen.

The current state of this research is mainly concerned with recording the current state of interconnected SC with respect to $\mathrm{CE}$. Future research will focus primarily on using the knowledge gained and focusing more specifically on analysis as well as optimization. This is to be achieved primarily through improved communication and information exchange between the EOL and the BOL, thus enabling a holistic improvement of current value streams. The aim should be to transfer the EOL decision-criteria (e.g., green PET-bottle goes to clothing industry, sleeve prevents a successful detection of the bottle material, etc.) towards the BOL, so the design-phase. This way, the design can be better adapted towards the needs and capabilities of the EOL. This should not only be the case for packaging, but also all other kind of products. 


\section{References}

Anderson, Elizabeth. 2017. "Extended Value Stream Mapping: Creating a Supply Chain View of Phytosanitary Compliance for Export Timber." Lincoln University.

Azevedo, Susana Garrido, Radu Godina, and João Carlos de Oliveira Matias. 2017. "Proposal of a Sustainable Circular Index for Manufacturing Companies." Resources 6(4). doi: 10.3390/resources6040063.

Bocken, Nancy M. P., Elsa A. Olivetti, Jonathan M. Cullen, José Potting, and Reid Lifset. 2017. "Taking the Circularity to the Next Level: A Special Issue on the Circular Economy." Journal of Industrial Ecology 21(3):476-82. doi: $10.1111 /$ jiec.12606.

Ciarapica, Filippo Emanuele, Maurizio Bevilacqua, and Giovanni Mazzuto. 2016. "Performance Analysis of New Product Development Projects: An Approach Based on Value Stream Mapping." International Journal of Productivity and Performance Management 65(2):177-206. doi: 10.1108/IJPPM06-2014-0087.

Costin-Weiterschan, Saskia, and Chrysoula Matiou. 2017. "VALUE STREAM IN THE - CASE STUDY OF THE SECOND-HAND.” University of Boras.

Dadashnejad, Ali Asghar, and Changiz Valmohammadi. 2019. "Investigating the Effect of Value Stream Mapping on Overall Equipment Effectiveness: A Case Study." Total Quality Management and Business Excellence 30(3-4):466-82. doi: 10.1080/14783363.2017.1308821.

Edtmayr, Thomas, Alexander Sunk, and Wilfried Sihn. 2016. “An Approach to Integrate Parameters and Indicators of Sustainability Management into Value Stream Mapping." Procedia CIRP 41:289-94. doi: 10.1016/j.procir.2015.08.037.

EMF. 2015. "Towards a Circular Economy: Business Rationale for an Accelerated Transition.” Ellen MacArtbur Foundation (EMF) 20.

Erlach, K. 2013. Value Stream Design. Springer Berlin Heidelberg.

European Parliamanet and Council of the European Union. 2008. "Directive 2008/98/EC of the European Parliament and of the Council of 19 November 2008 on Waste and Repealing Certain Directives (Text with EEA Relevance)." 
Faulkner, William, and Fazleena Badurdeen. 2014. "Sustainable Value Stream Mapping (Sus-VSM): Methodology to Visualize and Assess Manufacturing Sustainability Performance." Journal of Cleaner Production 85:8-18. doi: 10.1016/j.jclepro.2014.05.042.

Fink, Arlene. 2019. Conducting Research Literature Reviews - From the Internet to Paper. Fifth Edit. Los Angeles: SAGE Publications, Inc.

Galvão, Graziela Darla Araujo, Aline Sacchi Homrich, Martin Geissdoerfer, Steve Evans, Paulo Sergio scoleze Ferrer, and Marly M. Carvalho. 2020. "Towards a Value Stream Perspective of Circular Business Models." Resources, Conservation and Recycling 162(June 2019):105060. doi: 10.1016/j.resconrec.2020.105060.

Garza-Reyes, Jose Arturo, Joseth Torres Romero, Kannan Govindan, Anass Cherrafi, and Usha Ramanathan. 2018. "A PDCA-Based Approach to Environmental Value Stream Mapping (E-VSM)." Journal of Cleaner Production 180:335-48. doi: 10.1016/j.jclepro.2018.01.121.

González-Sánchez, Rocío, Davide Settembre-Blundo, Anna Maria Ferrari, and Fernando E. García-Muiña. 2020. "Main Dimensions in the Building of the Circular Supply Chain: A Literature Review." Sustainability (Switzerland) 12(6):1-25. doi: 10.3390/su12062459.

Grafström, Jonas, and Siri Aasma. 2021. "Breaking Circular Economy Barriers." Journal of Cleaner Production 292. doi: 10.1016/j.jclepro.2021.126002.

Hedlund, Christer, Petter Stenmark, Erik Noaksson, and Johan Lilja. 2020. "More Value from Fewer Resources: How to Expand Value Stream Mapping with Ideas from Circular Economy.” doi: 10.1108/IJQSS-05-2019-0070.

Huang, Zhuoyu, Jiwon Kim, Alireza Sadri, Steve Dowey, and Matthew S. Dargusch. 2019. "Industry 4.0: Development of a Multi-Agent System for Dynamic Value Stream Mapping in SMEs." Journal of Manufacturing Systems 52(April):1-12. doi: 10.1016/j.jmsy.2019.05.001.

ISO 22468. 2020. "Value Stream Management (VSM)."

Kirchherr, Julian, Denise Reike, and Marko Hekkert. 2017. "Conceptualizing the Circular Economy: An Analysis of 114 Definitions." Resources, Conservation and Recycling 127(April):221-32. doi: 10.1016/j.resconrec.2017.09.005.

Kuhlang, Peter, Thomas Edtmayr, Alexander Sunk, and Michael Hrach. 2014. "Further Development of Value Stream Mapping to Design Work Systems." in Proceedings of the 2014 Industrial and Systems Engineering Research Conference. 
Lorenzon dos Santos, Daniel, Ricardo Giglio, André L. Helleno, and Lucila M. S. Campos. 2019. "Environmental Aspects in VSM: A Study about Barriers and Drivers." Production Planning and Control 30(15):1239-49. doi: 10.1080/09537287.2019.1605627.

Lourenço, E. J., J. P. Pereira, R. Barbosa, and A. J. Baptista. 2016. "Using MultiLayer Stream Mapping to Assess the Overall Efficiency and Waste of a Production System: A Case Study from the Plywood Industry." Procedia CIRP 48:128-33. doi: 10.1016/j.procir.2016.04.086.

Di Maio, Francesco, Peter Carlo Rem, Kees Baldé, and Michael Polder. 2017. "Measuring Resource Efficiency and Circular Economy: A Market Value Approach." Resources, Conservation and Recycling 122:163-71. doi: 10.1016/j.resconrec.2017.02.009.

Mangers, Jeff, Meysam Minoufekr, and Peter Plapper. 2021. “An Innovative Strategy Allowing a Holistic System Change towards Circular Economy within Supply-Chains."

Mangers, Jeff, Christof Oberhausen, Meysam Minoufekr, and Peter Plapper. 2020. "Creation of an ISO Standard at the Example of Value Stream Management Method." Pp. 1-26 in Shaping the Future Through Standardization, edited by K. Jakobs. IGI Global.

Mangers, Jeff, Lou Thoussaint, Meysam Minoufekr, and Peter Plapper. 2020. "MULTI-LEVEL INFORMATION VALUE STREAM MAPPING." 147-56.

Matt, D. T., D. Krause, and R. Rauch. 2013. “Adaptation of the Value Stream Optimization Approach to Collaborative Company Networks in the Construction Industry." Procedia CIRP 12(December):402-7. doi: 10.1016/j.procir.2013.09.069.

Megayanti, Windy, Maria Anityasari, and Udisubakti Ciptomulyono. 2018. "Sustainable Suppy Chain Value Stream Mapping (Ssc-Vsm) the Application in Two Bottle Drinking Water Companies." Proceedings of the International Conference on Industrial Engineering and Operations Management 2018March:3573-85.

Merli, Roberto, Michele Preziosi, and Alessia Acampora. 2018. "How Do Scholars Approach the Circular Economy? A Systematic Literature Review." Journal of Cleaner Production 178:703-22. doi: 10.1016/j.jclepro.2017.12.112.

Meudt, Tobias, Joachim Metternich, and Eberhard Abele. 2017. "Value Stream Mapping 4.0: Holistic Examination of Value Stream and Information 
Logistics in Production." CIRP Annals - Manufacturing Technology 66(1):41316. doi: 10.1016/j.cirp.2017.04.005.

Moraga, Gustavo, Sophie Huysveld, Fabrice Mathieux, Gian Andrea Blengini, Luc Alaerts, Karel Van Acker, Steven de Meester, and Jo Dewulf. 2019. "Circular Economy Indicators: What Do They Measure?” Resources, Conservation and Recycling 146(March):452-61. doi: 10.1016/j.resconrec.2019.03.045.

Morseletto, Piero. 2020. “Targets for a Circular Economy.” Resources, Conservation and Recycling 153(October 2019):104553. doi: 10.1016/j.resconrec.2019.104553.

Mudgal, Devanshu, Emanuele Pagone, and Konstantinos Salonitis. 2020. "Approach to Value Stream Mapping for Make-To-Order Manufacturing." Procedia CIRP 93:826-31. doi: 10.1016/j.procir.2020.04.084.

Müller, Egon, Timo Stock, and Rainer Schillig. 2014. “A Method to Generate Energy Value-Streams in Production and Logistics in Respect of Time- and Energy-Consumption." Production Engineering 8(1-2):243-51. doi: 10.1007/s11740-013-0516-9.

Oberhausen, Christof. 2018. "Standardisierte Unternehmensübergreifende Wertstrommethode ( STREAM)."

Paju, Marja, Juhani Heilala, Markku Hentula, Antti Heikkilä, Björn Johansson, Swee Leong, and Kevin Lyons. 2010. "Framework and Indicators for a Sustainable Manufacturing Mapping Methodology." Proceedings - Winter Simulation Conference (December):3411-22. doi: 10.1109/WSC.2010.5679031.

Roosen, T. J., and D. J. Pons. 2013. "Environmentally Lean Production: The Development and Incorporation of an Environmental Impact Index into Value Stream Mapping." Journal of Industrial Engineering 2013:1-17. doi: 10.1155/2013/298103.

Rother, Mike, and John Shook. 1999. "Learning to See: Value Stream Mapping to Add Value and Eliminate Muda (Lean Enterprise Institute)." Lean Enterprise Institute Brookline.

Suarez-Barraza, Manuel F., José Miguel-Davila, and C. Fabiola Vasquez-García. 2016. "Supply Chain Value Stream Mapping: A New Tool of Operation Management." International Journal of Quality and Reliability Management 33(4):518-34. doi: 10.1108/IJQRM-11-2014-0171.

Vinodh, S., R. Ben Ruben, and P. Asokan. 2016. "Life Cycle Assessment Integrated Value Stream Mapping Framework to Ensure Sustainable 
Manufacturing: A Case Study." Clean Technologies and Environmental Policy 18(1):279-95. doi: 10.1007/s10098-015-1016-8.

WBCSD. 2018. “Circular Metrics Landscape Analysis.” (May 2018):35.

Yin, Robert K. 2018. Case Study Research and Applications: Design and Methods. Sixth edit. SAGE Publications, Inc.

\section{Appendix}

\begin{tabular}{|l|l|}
\hline Abbreviation: & Meaning: \\
\hline BOL & beginning-of-life \\
\hline C & costs \\
\hline D & distance \\
\hline DF & delivery frequency \\
\hline dif. & Different \\
\hline EOL & end-of-life \\
\hline fu & functional unit \\
\hline IT & idle time \\
\hline LT & lead time \\
\hline N & noise level \\
\hline NRG & energy-consumption \\
\hline OEM & original equipment manufacturer \\
\hline PR & product-weight \\
\hline PT & process time \\
\hline R-infrastructure & $\begin{array}{l}\text { This term is used for any infrastructure } \\
\text { needed to reintroduce resources into a } \\
\text { particular cycle. }\end{array}$ \\
\hline SCR & scrap-rate \\
\hline SL & same-loop \\
\hline W & weight \\
\hline WA & waste \\
\hline WC & water-consumption \\
\hline O & number of workers \\
\hline$\square$ & $\begin{array}{l}\text { macro: number of processes, } \\
\text { micro: number of machines }\end{array}$ \\
\hline
\end{tabular}

Table 2: Abbreviations of the individual indicators 